\title{
COVID-19 Pandemi Sürecinde Yenidoğanlarda Güvenli Maternal Bağlanma ve Emzirme
}

Safe Maternal Attachment and Breastfeeding in Newborns during the COVID-19 Pandemic Process

Gamzegül ALTAY ${ }^{1}$, Duygu ARIKAN ${ }^{2}$

\section{ÖZ}

Çin'de başlayarak kısa sürede tüm dünyada etkisini gösteren COVID-19 etkeni her yaş dönemini olumsuz bir şekilde etkilemiştir. Bu süreçte COVID19 pandemisi sebebiyle alınan tedbirler kapsamında uygulanan sosyal mesafe önlemleri özellikle yenidoğanlar ve anneleri için güvenli maternal bağlanma ve emzirme açısından güçlüklere neden olmaktadır. Maternal bağlanma ve emzirme yenidoğan döneminde olumlu etkilerinin başladığı ve uzun vadede yetișkinlik döneminde de bu etkilerin devam ettiği çok önemli uygulamalardır. Erken dönemde başlatılan anne-bebek etkileşimi ile emzirme süreci de olumlu bir şekilde gerçekleşmektedir. Fakat pandemi sürecinden kaynaklı hem maternal bağlanma hem de emzirme sürecinde aksaklıklar yaşanmaktadır. Dünya Sağlık Örgütü, Birleşmiş Milletler Çocuklara Yardım Fonu, Amerika Birleşik Devletleri Hastalık Önleme ve Kontrol Merkezi gibi uluslararası sağlık kuruluşları COVID-19 sürecinde emzirmenin kesintiye uğramamasını ve anne ile bebeğin bu süreçte birbirinden ayrılmaması gerektiğini belirtmektedir. $\mathrm{Bu}$ süreçte sağlık personellerinin güncel bilgilere doğru kaynaktan ulaşarak güvenli maternal bağlanmayı ve emzirmeyi sürdürmeleri önerilmektedir. Bu derlemede COVID-19 pandemi sürecinde yenidoğanlarda güvenli maternal bağlanma ve emzirme ilkeleri güncel kılavuzlar doğrultusunda incelenmiştir.

Anahtar Kelimeler: COVID-19, Emzirme, Maternal Bağlanma, Yenidoğan.

\begin{abstract}
The COVID-19 factor, which started in China and showed its effect all over the world in a short time, has negatively affected every age period. In this process, social distance measures implemented within the scope of the measures taken due to the COVID-19 pandemic cause difficulties in terms of secure maternal attachment and breastfeeding, especially for newborns and their mothers. Maternal attachment and breastfeeding are very important practices that have positive effects in the neonatal period and continue in adulthood in the long term. With the mother-infant interaction initiated in the early period, the breastfeeding process also takes place in a positive way. However, due to the pandemic process, there are disruptions in both maternal attachment and breastfeeding processes. International health organizations such as the World Health Organization, the United Nations International Children's Emergency Fund, Centers for Disease Control and Prevention state that breastfeeding should not be interrupted during the COVID-19 process and that the mother and baby should not be separated during this process. In this process, it is recommended that healthcare personnel maintain secure maternal attachment and breastfeeding by accessing up-to-date information from the right source. In this review, the principles of secure maternal attachment and breastfeeding in newborns during the COVID-19 pandemic were examined in line with current guidelines.
\end{abstract}

Keywords: COVID-19, Breastfeeding, Maternal Attachment, Newborn.

${ }^{1}$ Öğr. Gör. Gamzegül ALTAY, Çocuk Sağlığı ve Hastalıkları Hemşireliği, Recep Tayyip Erdoğan Üniversitesi, Sağlık Bilimleri Fakültesi, gamzegulaltay25@gmail.com, ORCID: 0000-0002-4895-5338

${ }^{2}$ Prof. Dr. Duygu ARIKAN, Çocuk Sağlığı ve Hastalıkları Hemşireliği, Atatürk Üniversitesi, Hemşirelik Fakültesi, darikan@atauni.edu.tr, ORCID: 0000-0001- 9451-8799 


\section{GİRIŞ}

İlk vakanın Çin'in Wuhan şehrinde Aralık 2019 tarihinde ortaya çıkması ile karşılaştığımız COVID-19 hastalığı kısa sürede dünya çapında birçok insanın ölümüne neden olmuş ve Dünya Sağl1k Örgütü (DSÖ) bu hastalığı pandemi olarak ilan etmiştir. ${ }^{1}$ COVID-19 ile enfekte birçok çocuk hasta olduğu bildirilse de COVID-19 ile enfekte yenidoğanın sınırlı sayıda olduğu belirtilmektedir., ${ }^{2,3}$

Pandemi sebebiyle alınan tedbirler sonucunda uygulanan sosyal mesafe önlemleri özellikle yenidoğanlar ve anneleri için maternal bağlanma ve emzirme açısından zorluklara neden olmaktadır. ${ }^{4}$ Enfekte bir anne ile bebeğini, doğum sonu dönemde çözülmesi gereken oldukça karmaşık problemler beklemektedir. Bunlar arasında anne ve bebeğin bu süreçte aynı odayı paylaşmaması ve emzirmenin güvenli bir şekilde sürdürülememesi yer almaktadır. ${ }^{5}$

Bağlanma, bir bireyin kendisi için önemli olan başka bireylere karşı hissettiği güçlü duygusal bağ olarak tanımlanmakta ve yenidoğan döneminde başlamaktadır. ${ }^{6}$ Özellikle yenidoğan döneminde geliştirilen ve bireylerin sonraki yaşamlarında sürdüreceği ilişkiler üzerinde etkili olan bağlanma kavramının, bu süreçte sağlıklı bir şekilde gerçekleştirilememesi ömür boyu devam eden ciddi sorunlara neden olabilir. ${ }^{7}$ Doğum sonrası erken dönemde anne ve bebek arasındaki yakın temasın ilerleyen yaşlarda nörogelişimsel faydaları olduğu yapılan bilimsel çalışmalar ile kanıtlanmıştır. ${ }^{8,9}$ Erken dönemde anne-bebek etkileşiminin sağlanması ile süt üretiminin düzenlenmesinde gerekli olan oksitosin salınımı artar ve bebeğin anneyi daha etkili emmesiyle sonuçlanır. ${ }^{10}$ Emzirmenin desteklenmesi sürecinde anne ve bebeğin aynı odayı paylaşmalarının; maternal bağlanmayı, emzirme sıklığını ve anne sütü oranını artırdığı uygulanan çalışmalarla kanıtlanmıştır. ${ }^{11,} 12$ Maternal bağlanma ve emzirmenin yenidoğan ve anne üzerindeki tüm bu olumlu etkilerine rağmen yaşanan pandemi nedeniyle doğum sonrası süreç sağlıklı bir şekilde yürütülememektedir.
$\mathrm{Bu}$ derlemede; COVID-19 pandemi sürecinde doğum sonrası erken dönemin en önemli aşamalarından biri olan maternal bağlanma ve emzirmenin yenidoğanlara bulaş riski olmadan güvenli bir şekilde nasıl sürdürülebileceği hakkında kanıt temelli ve güncel bilgilerin sunulması amaçlanmıştır.

\section{Yenidoğan ve COVID-19}

COVID-19 etkeni olan SARS-CoV-2 virüsü tüm yaş gruplarında hastalığa neden olabilir. COVID-19 uluslararası verilere göre çocuklarda daha hafif seyretmektedir ve mortalitesi erişkinlere oranla çok daha düşüktür. ${ }^{13}$ Hastalığın semptomlarının şiddetli görüldüğü çocuklar daha çok bir yaş altında olmasına karşın, bu çocukların iyileşme oranlarının yetişkin bireylere göre daha yüksek olduğu tespit edilmiştir. ${ }^{14}$

DSÖ verilerine göre, tüm nedenlere bağlı ölüm oranları incelendiğinde bir yaş altı çocuk ölümlerin \%50'den fazlasının yenidoğan döneminde olduğu belirtilmektedir. ${ }^{15}$ Yenidoğan dönemi çocukluk dönemleri içinde en hassas olanıdır ve bu dönemde bebeklerin bağışıklık sistemleri tam olarak gelişmemiştir. $\mathrm{Bu}$ durum pandeminin ortaya çıktığ 1 ilk günlerde COVID-19'un yenidoğanlarda nas1l seyredeceğini merak ve endişe konusu haline getirmiş, fakat süreç ilerlediğinde yenidoğanların korkulduğu kadar etkilenmediği görülmüştür. ${ }^{14}$ Uluslararası ilk veriler, bebeklerdeki enfeksiyonun \%1-5 oranında ve asemptomatik olduğunu aynı zamanda yetişkinlere göre daha hafif bir hastalık seyri gösterdiğini ortaya koymuştur. ${ }^{16}$ Ülkemizde ise 115 'i çocuk 2'si yenidoğan olmak üzere toplam 117 COVID19 ile enfekte çocuk değerlendirilmiş ve mortalitenin olmadığı bildirilmiştir. ${ }^{17}$

Çin'de yapılan bir çalışmada COVID-19 pozitif annelerden doğan 6 yenidoğan bebek ve anneden amnion sivisi, umblikal kord kan1, nazofarenks sürüntüsü ve anne sütü örnekleri alınmış ve bu örneklerin hiçbirinde COVID-19 etkenine rastlanmadığ1 bildirilmiştir. ${ }^{18}$ Vertikal geçişi kanıtlayan bir çalışma olmadığı gibi annelerden bebeklere 
dikey geçişi destekleyen güvenilir bir kanıt bildirilmemiştir. ${ }^{18}$

\section{COVID-19 Pandemi Sürecinde Maternal Bağlanma}

Maternal bağlanma, intrauterin dönemde başlayan ve doğum sonu dönem boyunca devam eden anne ve bebek arasinda kurulan her iki tarafin da yüksek haz duyduğu benzersiz bir bağlanma türüdür. ${ }^{6,} 19$ Doğum sonrası erken dönemde geliştirilen maternal bağlanma, bireyin yaşamı boyunca sürdüreceği insan ilişkileri üzerinde oldukça etkili bir kavramdır. ${ }^{20}$ Doğum sonu erken dönemde anne ve bebek arasındaki bağlanma sürecinin etkin ve güvenli bir şekilde başlatılması ile sadece bebeğin güven duygusunun gelişmesi desteklenmekle kalmayıp aynı zamanda annenin rolüne uyum sağlaması da kolaylaşır. ${ }^{6}$

Anne-bebek bağlanmasını kolaylaştırarak, doğum sonrası erken dönemde bağlanmayı etkileyen uygulamalar arasında, anne ile bebek arasında erken dönemde ten tene temasın sağlanması, kanguru yöntemi ve anne ile bebeğin doğum sonrasında aynı odayı paylaşmaları yer almaktadır. ${ }^{21}$ Fakat COVID-19 sürecinde enfekte ya da şüpheli olan annelerin bebekleri ile aynı odayı paylaşmaması, bebeğe olan bulaş riskini azaltmak için önerilmektedir, ancak bu durumun olumsuz sonuçlara neden olabileceği de unutulmamalıdır. ${ }^{22}$ Annenin bebeği ile aynı odada kalmaması ve bundan kaynaklı ihtiyaçlarına cevap verememesi ile ten tene temasın sağlanamaması anne için stresli bir süreçtir ve bu durumdan dolayı emzirme süreci de olumsuz etkilenmektedir. Annenin stresli olması durumunda bu bebeğe de yansiyabilir ve yenidoğanda da stres belirtileri gözlemlenebilir. Tüm bunların bağlanma üzerine olumsuz etkileri söz konusudur. ${ }^{23}$

Anne-bebek bağlanma süreci kırılgandır ve bu süreçte meydana gelen bir ayrılık durumunda ilerleyen y1llarda nörogelişimsel engeller ciddi bir sorun olarak karșımıza çıabilir. ${ }^{24}$ DSÖ, COVID-19 șüphesi olan veya tanı almış annelerin hastanede bakıma ihtiyacı olmadı $\breve{g}$ sürece bebeklerinden ayrılmaması gerektiğini ve bu süreçte rutin bakım uygulamalarının yapılabileceğini belirtmiștir. ${ }^{25}$ Amerika Birleșik Devletleri Hastalık Önleme ve Konrol Merkezi (CDC) ise șüpheli veya COVID-19 tanılı anne ve bebeğinin aynı odayı paylaşıp paylașmaması gerektiğine anne ve sağlık ekibinin beraber karar vermesi gerektiğini ve her anne ile bebeğinin bulunduğu durumun ayrı ayrı değerlendirilerek kişiye özel karar alınmasını önermektedir. ${ }^{26}$ Karar verme aşamasında; anne ve bebeğin sağlık-hastalık süreci, annenin kronik bir hastalığının olup olmamas1, bebeğin test sonucu, annenin emzirme konusundaki tutumu, klinik şartlar, annenin bebeği ile ayrılık durumuna bakış açısı ve anne-bebek ayrılığının ortaya çıkarabileceği diğer sonuçlar dikkate alınarak bir değerlendirme yapılmalıdır. ${ }^{23}$

Anne ve bebeğin ayrılması durumunda ise bebek sağlıklı bebeklerden ayrılarak izole edilmeli ve bakımını sağlayacak olan sağlık personeli koruyucu ekipman kullanmalıdır. ${ }^{23}$ Anne ve bebeğin ayrı kalması gerektiği düşünülmesine rağmen uygulanamazsa; anne emzirme ve rutin bakım uygulamaları esnasında maske kullanmalı, bebeği ile temas etmeden önce ve beslenme esnasinda el hijyenini sağlamalı, bakım sırasında maskeye ilaveten yüz maskesi kullanılmalı ve bakım ve emzirme saatleri dışında anne ile bebek arasında yaklaşık iki metre mesafe bulunmalıdır. ${ }^{23}$

\section{COVID-19 Pandemi Sürecinde Anne Sütü ve Emzirme}

Anne sütü, yenidoğanlar için en uygun besin olarak tanımlanmaktadır. ${ }^{27}$ DSÖ bebeklerin doğumdan sonraki ilk 30 dakika içerisinde emzirilmesini, ilk 6 ay sadece anne sütü ile beslenmesini, 24 ay ve sonrasina kadar tamamlayıcı besinler eklenerek emzirilmeye devam edilmesini önermektedir. $^{28,}{ }^{29} \mathrm{Bu}$ öneriler bebek sağlığını korumaktadır, çünkü anne sütünün yenidoğanları bakteriyel ve viral enfeksiyonlardan kaynaklı hastalık ve sakatlıklardan korumasinın yanı sira anne ve bebek sağlığı açısından da birçok faydasının olduğu bilinmektedir. ${ }^{29}$

COVID-19'un emzirme yoluyla bulaştı ğ konusunda mevcut bir kanit bulunmamakla 
beraber bu veri sınırlı çalışmalara dayanmaktadır. ${ }^{26,30}$ COVID-19 tanısı almış annelerle yapılan bir çalışmada, uygun hijyen ve izolasyon önlemleri ile yenidoğanların anneleriyle aynı odada kalmasinın ve emzirilmesinin güvenli olduğu ve yenidoğanlarda COVID-19 etkenine rastlanmadiğ 1 belirlenmiştir. ${ }^{31}$ CDC ise COVID-19 tanılı annelerin sütünde virüs etkeninin bulunmadığını, fakat virüsle savaşacak antikorların bulunduğunu bildirmiştir. $^{26}$ Fakat virüsün doğum sonu dönemde respiratuvar yol ile anneden yenidoğana geçip geçemeyeceği konusunda endişeler mevcuttur. ${ }^{30}$

Bulaşıcı hastalıklar ile enfekte olma açısından bakıldığında; emzirmenin kontrendike olup olmama durumu göz önünde bulundurulmalıdır. ${ }^{1}$ Bazı araştırmacılar pandemi dönemi boyunca riskli yenidoğanlara minimum 14 gün süre ile izolasyon uygulanmasinı ve bu zaman içerisinde emzirmenin gerçekleştirilmemesi gerektiğini bildirmiştir. ${ }^{18}{ }^{32}$ Bazı araştırmacılar ise bu görüşü doğru bulmadıklarını belirterek anne sütünün başlı başına bir COVID-19 etkenine bulaş aracı olmadığı gibi bunun aksine yenidoğanı olası bir COVID-19 enfeksiyonundan koruyucu spesifik antikorlar içerdiğini bildirmiştir. ${ }^{31}$ Ayrıca, asemptomatik COVID-19 enfeksiyonu durumunda, bebeği annesinden rutin olarak ayırma uygulamasının, annebebek ilişkisini ve emzirmeyi olumsuz olarak etkileyeceği için uygun olmadığ bildirilmiştir. ${ }^{33}$ Eğer annenin sağlığ 1 doğrudan emzirmek için uygun değilse ve emzirme önerilmiyorsa, sağılan anne sütünün uygun koşullarda muhafaza edilerek kullanılabileceği bildirilmiştir. ${ }^{1,33}$

Tablo 1'de yer alan COVID-19 şüpheli veya tanılı anne ile yenidoğanlar için uluslararası kılavuzlar incelendiğinde; şüpheli veya tanı alan annelerden doğan yenidoğanlar için emzirme desteklenmiştir. ${ }^{26}$, 34 Aynı zamanda DSÖ, UNICEF (Birleşmiş Milletler Çocuklara Yardım Fonu), Emzirme Tıbbı Akademisi gibi uluslararası sağlık örgütleri de bu süreçte uygun damlacık yolu izolasyon yöntemlerinin uygulanması koşuluyla emzirmeyi önermişlerdir. ${ }^{25,}$ 35, 36 DSÖ, salgınlar gibi beklenmedik ve olağanüstü durumların emzirmeyi aksatmak veya sonlandırmak için yeterli bir gerekçe olmadığını belirtmiştir. ${ }^{37}$

DSÖ ve bazı uluslararası kuruluşların COVID-19 tanisi alan veya semptomları olan annelerin, koruyucu tedbirler sonras1 bebeğini emzirmesinin mümkün olabileceği gibi bebeğe sağılmış süt verebileceğini de bildirmektedir. Annelerin emzirme esnasında alması gereken önlemler ile sütünü sağarak vermesi gereken durumlarda uymasi gereken bazı kurallar aşağıda belirtilmiştir. ${ }^{26,36,37}$

- Emzirme öncesinde el hijyeni sağlandiktan sonra, ağız ve burnu kapatacak biçimde cerrahi maske kullanılmalıdır.

- Bebeğe temas öncesi ve sonrasinda eller su ve sabun ile 20 saniye boyunca yıkanmalıdır.

- Dokunulan tüm yüzeyler rutin bir şekilde dezenfektan kullanılarak temizlenmelidir.

- Pompa ile sütün sağıldığı durumlarda; kişiye ait gögüs pompası kullanılmalı ve rutin olarak temizlenmelidir.

- Sağma işlemi esnasında maske kullanılmalı, anne sütünü sağmadan önce ellerini su ve sabun ile yıkamalıdır.

- Anne sütü sağılarak verilecek ise COVID-19 enfeksiyonu açısından risk grubunda olmayan sağlıklı bir bakım verici tarafindan bebeğe verilmelidir. ${ }^{26 \text {, }}$ 35

\section{COVID-19 Pandemi Sürecinde Maternal Bağlanma ve Emzirmeyi Desteklemede Sağlık Çalışanlarının Önemi}

Postpartum dönemi, ebeveynlerin yeni rollerini öğrenmeye çalıştıkları, fizyolojik ve psikolojik değişikliklerin yaşandığı karmaşık bir süreçtir. $\mathrm{Bu}$ karmaşı süreç içerisinde başlatılacak olan bağlanma ilişkisinin gerçekleşmesinde anneden, bebekten ve diğer faktörlerden kaynaklı birtakım sorunlar olabilir. 
Tablo 1. COVID-19 Şüpheli veya Tanılı Anne ile Yenidoğanlar İçin Kılavuzlar ${ }^{4}$

\begin{tabular}{|c|c|c|c|c|c|}
\hline Yönerge & $\begin{array}{l}\text { Doğum sonrası } \\
\text { ayrılık }\end{array}$ & $\begin{array}{l}\text { Anne COVID-19 } \\
\text { Pozitif }\end{array}$ & $\begin{array}{l}\text { COVID-19 } \\
\text { tanılı } \\
\text { anneden } \\
\text { anne süitü }\end{array}$ & $\begin{array}{l}\text { Yenidoğan } \\
\text { COVID-19 } \\
\text { pozitif }\end{array}$ & $\begin{array}{l}\text { Yenidoğan } \\
\text { COVID-19 } \\
\text { negatif }\end{array}$ \\
\hline Çin $^{18}$ & $\begin{array}{l}\text { Anne ile bebek } \\
\text { ayrilır }\end{array}$ & $\begin{array}{l}\text { Negatif olana kadar } \\
\text { bebekten ayrilma }\end{array}$ & HAYIR & $\begin{array}{l}\text { Karantinaya } \\
\text { alınır }\end{array}$ & Rutin bakım \\
\hline $\mathbf{A B D}^{26}$ & $\begin{array}{l}\text { Anne kabul } \\
\text { ederse ve ayr1 } \\
\text { bir alan } \\
\text { mevcutsa }\end{array}$ & $\begin{array}{l}\text { Negatif olana kadar } \\
\text { bebekten ayrilma } \\
\text { (en az } 14 \text { gün) }\end{array}$ & EVET & $\begin{array}{l}\text { Hastane veya } \\
\text { evde en az } 14 \\
\text { gün karantina }\end{array}$ & Rutin bakım \\
\hline $\begin{array}{l}\text { Avrupa } \\
\text { Ülkeleri }^{34}\end{array}$ & $\begin{array}{l}\text { Anne ve } \\
\text { bebeğin } \\
\text { hastanede } \\
\text { bakıma } \\
\text { ihtiyaçları yoksa } \\
\text { ayrılmaz }\end{array}$ & $\begin{array}{l}\text { Anne damlacık yolu } \\
\text { ile izolasyon } \\
\text { önlemlerini alır ve } \\
\text { ayrılık olmaz }\end{array}$ & EVET & $\begin{array}{l}\text { Anneyle en az } \\
14 \text { gün } \\
\text { hastanede veya } \\
\text { evde karantina. } \\
\text { (Maternal } \\
\text { damlacık } \\
\text { önlemleri) }\end{array}$ & Rutin bakım \\
\hline $\begin{array}{l}\text { Dünya Sağlık } \\
\text { Örgüitü }^{25}\end{array}$ & HAYIR & $\begin{array}{l}\text { Anne veya bebeğin } \\
\text { hastanede bakıma } \\
\text { ihtiyaçları olmadı̆̆ } \\
\text { sürece ayrılık yok }\end{array}$ & EVET & $\begin{array}{l}\text { Anneyle en az } \\
14 \text { gün } \\
\text { hastanede veya } \\
\text { evde karantina. } \\
\text { (Maternal } \\
\text { damlacik } \\
\text { önlemleri) }\end{array}$ & Rutin bakım \\
\hline $\begin{array}{l}\text { Emzirme } \\
\text { Tıbbı } \\
\text { Akademisi }^{35}\end{array}$ & HAYIR & $\begin{array}{l}\text { Anne veya bebeğin } \\
\text { hastanede bakıma } \\
\text { ihtiyaçları olmadı̆̆ } \\
\text { sürece ayrılık yok }\end{array}$ & EVET & $\begin{array}{l}\text { Anneyle en az } \\
14 \text { gün } \\
\text { hastanede veya } \\
\text { evde karantina. } \\
\text { (Maternal } \\
\text { damlacik } \\
\text { önlemleri) }\end{array}$ & Rutin bakım \\
\hline UNICEF $^{36}$ & HAYIR & $\begin{array}{l}\text { Anne veya bebeğin } \\
\text { hastanede bakıma } \\
\text { ihtiyaçları olmadığ } \\
\text { sürece ayrılık yok }\end{array}$ & EVET & $\begin{array}{l}\text { Anneyle en az } \\
14 \text { gün } \\
\text { hastanede veya } \\
\text { evde karantina. } \\
\text { (Maternal } \\
\text { damlac1k } \\
\text { önlemleri) }\end{array}$ & Rutin bakım \\
\hline $\begin{array}{l}\text { T.C. Sağlık } \\
\text { Bakanlığı }^{38}\end{array}$ & HAYIR & $\begin{array}{l}\text { Annede klinik } \\
\text { olarak hastalık } \\
\text { semptomları varsa } \\
\text { anne ile bebek } \\
\text { ayr1lır. }\end{array}$ & EVET & $\begin{array}{l}\text { Asemptomatik } \\
\text { anne ve } \\
\text { bebekler birlikte } \\
\text { izole edilir. } \\
\text { (Maternal } \\
\text { damlac1k } \\
\text { önlemleri) }\end{array}$ & Rutin bakım \\
\hline
\end{tabular}

COVID-19 pandemi süreci de bu faktörlerden biridir. Sağlik profesyonelleri güvenli maternal bağlanmanın oluşmasında ortaya çıkabilecek sorunları tanımlamalı ve çözüm aşamasında ailelere danışmanlık yapmalıdırlar. ${ }^{39} \mathrm{Bu}$ amaçla maternal bağlanmanın güvenli bir şekilde başlatılarak sürdürülmesi için kanıta dayalı uygulamalar olan, bebek ve annenin aynı oday1 paylaşması (rooming-in), bebeğin emzirilmesi (emzirme esnasında annenin bebeğini kucağına alarak göz teması kurmas1) ve annenin emzirme esnasinda kendisini güvende ve rahat hissetmesinin sağlanmasında sağlık profesyonellerinin rolü son derece önemlidir. ${ }^{40}$ 
Doğum sonrası erken dönemde başlayarak uygulanan ve bireylerin sonraki hayatlarının şekillenmesinde basit ve etkili bir uygulama olan maternal bağlanma ve emzirme, küresel bir salgın haline gelen COVID-19 enfeksiyonu sebebiyle kesintiye uğramakta ve aksamaktadır. Yenidoğan döneminde bakım veren sağlık profesyonelleri, COVID-
19 süreci nedeniyle hızla değișen sağl1k sistemine adaptasyon sağlamaya çalışırken bir yandan da yenidoğan ve annenin desteklenmesindeki uygulamaları sürdürmek için çaba göstermektedir. Bu süreçte sağlik personellerinin güncel bilgilere doğru kaynaktan ulaşarak anne-bebek bağlanmasını sürdürmeleri büyük önem taşımaktadır.

\section{SONUÇ VE ÖNERILER}

COVID-19 pandemi sürecinde maternal bağlanma ve emzirmenin güvenli bir şekilde sürdürülmesine ilişkin yayımlanan kılavuzlar ve literatürde yer alan güncel çalışma sonuçları 1şı̆̆ında hazırlanan bu derlemede aşağıdaki sonuçlara ulaşılmıştır:

- COVID-19 tanısı almış olan annelerin hastane ortamında bakıma ihtiyaçları yoksa, anne ve yenidoğan birbirinden ayrılmamalı ve maternal bağlanma desteklenmelidir.

- COVID-19 pandemi sürecinde şüpheli veya tanı almış olan annelerin, damlacık yolu ile izolasyon önlemlerini alarak bebeklerini emzirebilecekleri belirtilmiştir.
- Anneler ile sağlık çalışanları bebeğin emzirilmesi konusunda birlikte karar almalidir.

- Emzirmek istemeyen annelerin bebeklerine anne sütü verilmesini desteklemek için sağılmış anne sütü verilebilir.

- Maternal bağlanma ve emzirmenin yenidoğan dönemi ve bundan sonraki dönemler üzerine olan etkileri düşünüldüğünde annelerin bu konuda desteklenmesi ve teşvik edilmesi gerekmektedir.
1. Yang, N, Che, S, Zhang, J, Wang, X, Tang, Y, Wang, J. et al. (2020). "Breastfeeding of Infants Born To Mothers with COVID-19: A Rapid Review". Annals of Translational Medicine, 8 (10), 618.

2. Ma, X, Zhu, J. and Du, L. (2020). "Neonatal Management During the Coronavirus Disease (COVID-19) Outbreak: The Chinese Experience". NeoReviews, 21 (5), e293-e297.

3. Panahi, L, Amiri, M. and Pouy, S. (2020). "Clinical Characteristics of COVID-19 Infection in Newborns and Pediatrics: A Systematic Review". Archives of Academic Emergency Medicine, 8 (1), e50

4. Tscherning, C, Sizun, J. and Kuhn, P. (2020). "Promoting Attachment between Parents and Neonates Despite the COVID19 Pandemic". Acta Paediatrica, 109 (10), 1937-1943.

5. TJOD İstanbul Bülteni. (2020). "COVID-19 özel sayısı". Erişim adresi: index (tjodistanbul.org) (Erişim Tarihi: 02 Aralık 2020).

6. Nacar, E.H. ve Gökkaya, F. (2019). "Bağlanma ve Maternal Bağlanma Konusunda Bir Derleme”. Kıbrıs Türk Psikiyatri ve Psikoloji Dergisi, 1 (1), 50-56.

7. Meredith, P.J, Strong, J. and Feeney, J.A. (2007). “Adult Attachment Variables Predict Depression before and after Treatment for Chronic Pain”. European Journal of Pain, 11 (2), 164-170.
8. Peters, K.L, Rosychuk, R.J, Hendson, L, Coté, J.J, Mc Pherson, C. and Tyebkhan, J.M. (2009). "Improvement of Short-and Long-Term Outcomes for Very Low Birth Weight Infants: Edmonton NIDCAP Trial”. Pediatrics, 124 (4), 1009-20.

9. Charpak, N, Tessier, R, Ruiz, J.G, Hernandez, J.T, Uriza, F, Villegas, J. et al. (2017). "Twenty-year Follow-Up of Kangaroo Mother Care Versus Traditional Care”. Pediatrics, 139 (1), e20162063.

10. Jaafar, S.H, Ho, J.J. and Lee, KS. (2016). "Rooming-in for New Mother and Infant Versus Separate Care for Increasing The Duration of Breastfeeding". The Cochrane Database of Systematic Reviews, 26 (8), CD006641.

11. Blair, P.S. and Ball, H.L. (2004). "The Prevalence and Characteristics Associated with Parent-Infant Bed-Sharing in England". Archives of Disease in Childhood, 89 (12), 11061110

12. Çınar, N, Sözeri, C, Dede, C. ve Cevahir, R. (2010). "Anne ve Bebeğin Aynı Odada Uyumasının Emzirmeye Etkisi”. Maltepe Üniversitesi Hemşirelik Bilim ve Sanatı Dergisi, 235-241.

13. Dong, Y, Mo, X, Hu, Y, Qi, X, Jiang, F, Jiang, Z. and Tong, S (2020). "Epidemiology of COVID-19 among Children in China". Pediatrics, 145 (6), e20200702.

14. Sinha, IP, Harwood, R, Semple, MG, Hawcutt, DB, Thursfield, R, Narayan, O. et al. (2020). "COVID-19 Infection in children”. The Lancet Respiratory Medicine, 8 (5), 446-447.

15. Wold Health Organization. (2020). "Infant Mortality Rate (Deaths per 1000 Live Births)". Erişim adresi: 
https://www.who.int/data/gho/data/indicators/indicatordetails/GHO/infant-mortality-rate-(deaths-per-1000-livebirths). (Erişim tarihi: 03 Aralık 2020).

16. Ludvigsson, J.F. (2020). "Systematic review of COVID-19 in Children Shows Milder Cases and A Better Prognosis Than Adults". Acta Paediatrica, 109 (6), 1088-1095.

17. Tezer, H. and Demirdağ, T. (2020). "Novel Coronavirus Disease (COVID-19) in Children". Turkish Journal of Medical Sciences, 50, 592-603

18. Chen, H, Guo, J, Wang, C, Luo, F, Yu, X, Zhang, W. et al (2020). "Clinical Characteristics and Intrauterine Vertical Transmission Potential of COVID-19 Infection İn Nine Pregnant Women: A Retrospective Review of Medical Records". Lancet, 395 (10226), 809-15.

19. Ard, N.C. (2000). "Prenatal and Postnatal Attachment in Adolescent Mother". Journal of Child and Family Nursing, 3 (5), 313-325

20. Fraley, R.C. and Shaver, PR. (2000). "Adult Romantic Attachment: Theoretical Developments, Emerging, Controversies and Unanswered Questions". Review of General Psychology, 4 (2), 132-154.

21. Moore, E.R, Anderson, G.C. and Bergman, N. (2007). "Early Skin-To-Skin Contact for Mothers and Their Healthy Newborn Infants". The Cochrane Database of Systematic Reviews, (3), CD003519.

22. Stuebe A. (2020). "Should Infants Be Separated from Mothers with COVID-19? First, Do No Harm”. Breastfeeding Medicine, 15 (5), 351-352.

23. Vincenzo, B. and Hughes, B. (2020). "Coronavirus disease 2019 (COVID-19): Pregnancy issues”. Erişim adresi: https://www.uptodate.com/contents/coronavirus-disease-2019covid-19-pregnancy-issues-and-antenatal-care. (Erişim tarihi: 09 Aralik 2020).

24. López-Maestro, M, Sierra-Garcia, P, Diaz-Gonzalez, C, TorresValdivieso, M.J, Lora-Pablos, D, Ares-Segura, S. et al. (2017). "Quality of Attachment in Infants less than 1500g or less than 32 Weeks. Related Factors". Early Human Development, 104 (2017), 1-6. https://doi.org/10.1016/j.earlhumdev.2016.11.003

25. Wold Health Organization. (2020). "Coronavirus Disease (COVID-19) Pandemic". Erişim adresi: https://www.who.int/ emergencies/diseases/novel-coronavirus2019?gclid=EAIaIQob ChMIw77zqoys6QIVA7DtCh0icga6EAAYASAAEgIGCfD_B wE (Erişim tarihi: 09 Aralık 2020).

26. Centers for Disease Control and Prevention (2020). "Coronavirus Disease (COVID-19) and Breastfeeding". Erişim adresi: https://www.cdc.gov/breastfeeding/breastfeedingspecial-circumstances/maternal-or-infant-illnesses/covid-19and-breastfeeding.html (Erişim tarihi: 06 Aralık 2020).

27. World Health Organization. (2004). "Guiding Principles for Feeding Infants and Young Children During Emergencies". Erișim adresi: https://www.who.int/nutrition/publications/emer gencies/9241546069/en/ (Erişim tarihi: 06 Aralık 2020).

28. WHO and United Nations Children's Fund. (2003). "Global Strategy for Infant and Young Child Feeding”. Erișim adresi: https://www.who.int/nutrition/publications/infantfeeding/92415 62218/en/ (Erişim tarihi: 11 Aralık 2020).

29. Yurtdaș, G, Calık, G, Yalçın, T. ve Kaner, G. (2020). "COVID19 Pandemi Sürecinde Anne Sütü ile Beslenmenin Önemi”. İzmir Katip Çelebi Üniversitesi Sağlık Bilimleri Fakültesi Dergisi, 5 (2), 153-158.

30. El-Gilany, AH. (2020). "COVID-19 and Breastfeeding”. Asp Biomed Clin Case Rep, 3 (2), 102-105.
31. Salvatore, C.M, Han, J.Y, Acker, K.P, Tiwari, P, Jin, J, Brandler, M, Cangemi, C, Gordon, L, Parow, A, DiPace, J. and DeLaMora, P. (2020). "Neonatal Management and Outcomes during the COVID-19 Pandemic: an Observation Cohort Study". The Lancet Child \& Adolescent Health, 4 (10), 721 727.

32. Li, F, Feng, Z.C. and Shi, Y. (2020). "Proposal for Prevention and Control of The 2019 Novel Coronavirus Disease in Newborn Infants". Archives of Disease in Childhood. Fetal and Neonatal Edition, 105 (6), 683-684.

33. Fernández-Carrasco, FJ, Vázquez-Lara, J.M, González-Mey, U, Gómez-Salgado, J, Parrón-Carreño, T. and Rodríguez-Díaz, L. (2020). "Coronavirus Covid-19 Infection and Breastfeeding: An Exploratory Review". Revista Espanola de Salud Publica, 94, e202005055.

34. Davanzo, R, Moro, G, Sandri, F, Agosti, M, Moretti, C. and Mosca, F. (2020). "Breastfeeding and Coronavirus Disease2019: Ad Interim Indications of the Italian Society of Neonatology Endorsed by the Union of European Neonatal \& Perinatal Societies". Maternal \& Child Nutrition, 16 (3), e13010.

35. Academy of Breastfeeding Medicine. (2020). "ABM Statement on Coronavirus 2019 (COVID-19)". Erişim adresi: https://www.bfmed.org/abm-statement-coronavirus (Erisim tarihi: 06 Aralık 2020).

36. United Nations International Children's Emergency Fund. (2020). "Coronavirus Disease (COVID-19): What Parents Should Know". Erişim adresi: https://www.unicef.org/stories/ novel-coronavirus-outbreak-what-parents-should-know (Erişim tarihi: 06 Aralık 2020).

37. World Health Organization. (2020). "Coronavirus Disease (COVID-19): Pregnancy and Childbirth”. https://www.who.int/ news-room/q-a-detail/coronavirus-disease-covid-19-pregnancyand-childbirth (Erişim tarihi: 06 Aralık 2020).

38. T.C. Sağlık Bakanlığı (2021). "COVID-19 Cocuk Hasta Yönetimi ve Tedavi”. Erişim adresi: https://covid19.saglik.gov. tr/TR-66342/cocuk-hasta-yonetimi-ve-tedavi.html (Erișim tarihi: 30 Haziran 2021).

39. Yıldızhan, E. (2017). "Bağlanma Teorisi ve Bağlanma Bozukluklarına Genel Bir Bakış". Anatol Clin, 22, 66-72.

40. Köse, D, Çınar, N. ve Altınkaynak, S. (2013). "Yenidoğanın Anne ve Baba ile Bağlanma Süreci”. Sürekli Tıp Eğitim Dergisi, 22 (6), 239-45 